\title{
Bananeiras consorciadas com leguminosas herbáceas perenes utilizadas como coberturas vivas
}

\author{
José Antonio Azevedo Espindola(1), José Guilherme Marinho Guerra ${ }^{(1)}$, Adriano Perin ${ }^{(2)}$, \\ Marcelo Grandi Teixeira ${ }^{(1)}$, Dejair Lopes de Almeida ${ }^{(1)}$, Segundo Urquiaga ${ }^{(1)}$ e Rubens Nei Briançon Busquet ${ }^{(3)}$
}

\begin{abstract}
(1)Embrapa Agrobiologia, BR 465, Km 7, CEP 23851-970 Seropédica, RJ. E-mail: jose@cnpab.embrapa.br, gmguerra@cnpab.embrapa.br, grandi@cnpab.embrapa.br, dejair@cnpab.embrapa.br, urquiaga@cnpab.embrapa.br. (2)Centro Federal de Educação Tecnológica de Rio Verde, Rodovia Sul Goiana, Km 01, Caixa Postal 66, CEP 75901-970 Rio Verde, GO. E-mail: perinrj@yahoo.com.br (3)Universidade Federal Rural do Rio de Janeiro, Dep. de Fitotecnia, Km 7, BR 465, CEP 23890-000 Seropédica, RJ. E-mail: rbusquet@ufrrj.br
\end{abstract}

\begin{abstract}
Resumo - O objetivo deste trabalho foi avaliar a produção de bananeiras consorciadas com as leguminosas herbáceas perenes - amendoim forrageiro (Arachis pintoi), cudzu tropical (Pueraria phaseoloides) e siratro (Macroptilium atropurpureum). Os tratamentos-controle consistiram em vegetação espontânea com predomínio de Panicum maximum, e vegetação espontânea com adubação nitrogenada das bananeiras. Também foi avaliado o desenvolvimento vegetativo das bananeiras. Entre as coberturas avaliadas, a vegetação espontânea e o cudzu tropical apresentaram produções maiores de biomassa; o cudzu tropical proporcionou valores maiores para quantidades de $\mathrm{N}$ acumulado e derivado da fixação biológica. As leguminosas amendoim forrageiro, cudzu tropical e siratro proporcionaram desenvolvimento vegetativo mais rápido nas bananeiras consorciadas. Cudzu tropical e siratro promoveram maiores valores de peso dos cachos e das pencas. $\mathrm{O}$ uso das leguminosas avaliadas resulta em aumento da porcentagem de cachos colhidos e redução do tempo de colheita, além de proporcionar maior produtividade, quando comparado ao uso de vegetação espontânea.
\end{abstract}

Termos para indexação: adubação verde, fixação biológica de nitrogênio, plantas de cobertura do solo.

\section{Banana plants intercropped with perennial herbaceous legumes used as living mulches}

\begin{abstract}
The objective of this work was to evaluate the yield of banana plants intercropped with the perennial herbaceous legumes forage groundnut (Arachis pintoi), tropical kudzu (Pueraria phaseoloides) and siratro (Macroptilium atropurpureum). The control treatments were spontaneous vegetation (mainly Panicum maximum) and spontaneous vegetation plus nitrogen fertilizer application to banana plants. The vegetative growth of banana plants was also evaluated. Among the treatments, spontaneous vegetation and tropical kudzu promoted the highest dry matter productions; tropical kudzu had the highest amounts of accumulated and fixed N. Forage groundnut, tropical kudzu and siratro promoted the fastest vegetative growth for banana plants in this intercropped system. Tropical kudzu and siratro promoted the highest values for bunch weight and hands weight. All legume treatments result in a increase in the percentage of harvested bunches and a reduction in the harvesting time and are related to higher yields, compared to spontaneous vegetation treatment.
\end{abstract}

Index terms: green manure, biological nitrogen fixation, cover crops.

\section{Introdução}

A banana é um alimento altamente energético, com elevado conteúdo de carboidratos facilmente assimiláveis, fonte de vitaminas e minerais e com boa aceitação no mercado consumidor (Medina et al., 1995). O cultivo da bananeira é difundido em praticamente todos os estados brasileiros. Entre as espécies frutíferas, ocupa o segundo lugar em área plantada, sendo superada apenas pela laranja (IBGE, 2002).
Embora seu cultivo comercial seja recomendado preferencialmente para terrenos planos, a maioria dos plantios de banana do País localiza-se em áreas de declividade acentuada, o que exige a adoção de práticas de conservação do solo (Borges et al., 1997). O uso de plantas de cobertura do solo mostra-se uma estratégia de manejo para os agroecossistemas, possibilitando aumentos de produtividade associados à otimização de processos biológicos. Entre as vantagens trazidas por essa prática, podem ser destacados a proteção do solo 
contra agentes climáticos causadores de erosão (Derpsch et al., 1991), o controle de plantas de ocorrência espontânea (Espindola et al., 2000) e o aumento da disponibilidade de nutrientes ligados à matéria orgânica do solo (Canellas et al., 2004).

As leguminosas destacam-se entre as espécies empregadas como plantas de cobertura, principalmente por sua capacidade de fornecimento de $\mathrm{N}$ para as culturas de interesse comercial. Diversos mecanismos têm sido apontados para justificar a maior disponibilidade desse nutriente em áreas cultivadas com leguminosas, tais como a fixação de $\mathrm{N}$ atmosférico pela simbiose com bactérias diazotróficas e a recuperação do $\mathrm{N}$ lixiviado para camadas mais profundas do solo (Costa, 1993).

A identificação de plantas de cobertura mais adequadas para determinada região é importante para garantir o sucesso dessa prática. Com relação à cultura da bananeira, Borges et al. (1997) apontam diversas características desejáveis de uma planta para cobertura vegetal, como a produção de sementes viáveis, boa adaptação às condições edafoclimáticas, facilidade de manejo, resistência a pragas e doenças, competição com as plantas espontâneas e tolerância ao sombreamento. Um estudo sobre leguminosas herbáceas perenes submetidas a diferentes fontes e doses de fósforo na Baixada Fluminense constatou que amendoim forrageiro, cudzu tropical e siratro foram as espécies melhor adaptadas às condições edafoclimáticas daquela região (Espindola et al., 2005). Apesar de os resultados obtidos serem promissores, torna-se necessário observar o comportamento dessas plantas quando consorciadas com espécies frutíferas.

O objetivo deste trabalho foi avaliar o efeito da cobertura viva formada por leguminosas herbáceas perenes sobre a produção de bananeira cultivar Nanicão.

\section{Material e Métodos}

O experimento foi conduzido em um Argissolo Vermelho-Amarelo distrófico, localizado na área experimental da Embrapa Agrobiologia, no Município de Seropédica, RJ. A análise química do solo, segundo Embrapa (1997), na profundidade de 0,0-0,20 m, apresentou: $\mathrm{pH}$ em água, 4,4; $\mathrm{Al}, 2,0 \mathrm{mmol}_{\mathrm{C}} \mathrm{dm}^{-3}$; Ca, 25,0 $\mathrm{mmol}_{\mathrm{C}} \mathrm{dm}^{-3}$; $\mathrm{Mg}$, $14,0 \mathrm{mmol}_{\mathrm{C}} \mathrm{dm}^{-3}$; $\mathrm{P}, 3,0 \mathrm{mg} \mathrm{dm}^{-3} ; \mathrm{K}, 46,0 \mathrm{mg} \mathrm{dm}^{-3}$.

O delineamento experimental adotado foi o de blocos ao acaso, com quatro repetições. Os tratamentos foram formados por leguminosas herbáceas perenes consorciadas com a cultura da bananeira - amendoim forrageiro (Arachis pintoi Krap. \& Greg.), cudzu tropical (Pueraria phaseoloides (Roxb.) Benth.) e siratro (Macroptilium atropurpureum (OC.) Urb.) - e pelos controles, vegetação espontânea com predomínio de capim-colonião (Panicum maximum Jacq.) e vegetação espontânea acrescida de adubação nitrogenada nas bananeiras. Cudzu tropical e siratro têm hábito de crescimento volúvel, enquanto amendoim forrageiro e capimcolonião apresentam-se como espécies de hábitos rastejante e ereto, respectivamente.

O experimento foi implantado em maio de 1996, usando-se mudas de amendoim forrageiro produzidas em bandeja e sementes com rizóbio para as demais leguminosas. Em junho de 1998, foram plantadas mudas de bananeira cultivar Nanicão, subgrupo Cavendish (AAA), obtidas por cultura de tecidos. Cada unidade experimental constituiu-se de 16 bananeiras dispostas no espaçamento de $3 \times 3 \mathrm{~m}$. As mudas receberam, na fase de viveiro, $50 \mathrm{~cm}^{3}$ de inoculante misto contendo micélios e esporos dos fungos micorrízicos arbusculares Glomus clarum (57 esporos por muda) e Gigaspora margarita (18 esporos por muda).

A adubação de plantio consistiu na aplicação de $10 \mathrm{Mg} \mathrm{ha}^{-1}$ de esterco de curral curtido e $60 \mathrm{~kg} \mathrm{ha}^{-1}$ de $\mathrm{P}_{2} \mathrm{O}_{5}$, na forma de termofosfato, enquanto a adubação de formação foi realizada aplicando-se $30 \mathrm{~kg} \mathrm{ha}^{-1}$ de $\mathrm{K}_{2} \mathrm{O}$, na forma de cloreto de potássio, parcelados em julho e novembro do primeiro ano do cultivo, nas proporções de 1/3 e 2/3. As bananeiras do tratamento vegetação espontânea com adubação nitrogenada receberam, nesses mesmos meses, $40 \mathrm{~kg} \mathrm{ha}^{-1}$ de $\mathrm{N}$, na forma de uréia, parcelados nas proporções de $1 / 3$ e $2 / 3$. A adubação de manutenção foi realizada a partir do segundo ano de cultivo, colocando-se, anualmente, $20 \mathrm{~kg} \mathrm{ha}^{-1}$ de Fritted Trace Elements (FTE BR-12), $50 \mathrm{~kg} \mathrm{ha}^{-1}$ de $\mathrm{P}_{2} \mathrm{O}_{5}$ na forma de termofosfato e $200 \mathrm{~kg} \mathrm{ha}^{-1}$ de $\mathrm{K}_{2} \mathrm{O}$, na forma de cloreto de potássio. A aplicação de FTE BR-12 foi realizada em janeiro, enquanto o termofosfato e o cloreto de potássio foram parcelados em doses idênticas nos meses de janeiro e março. As bananeiras do tratamento vegetação espontânea com adubação nitrogenada também receberam $90 \mathrm{~kg} \mathrm{ha}^{-1}$ de $\mathrm{N}$, na forma de uréia, parcelados em doses idênticas em janeiro e março.

Realizaram-se três cortes das plantas de cobertura aos 11, 20 e 22 meses depois do plantio das leguminosas -, mantendo-se os resíduos vegetais sobre a superfície do solo. No momento de cada corte, foram coletadas amostras da parte aérea dessas plantas, para a estimativa da produção de biomassa aérea e dos teo- 
res de N. As amostras foram secadas em estufa à temperatura de $65^{\circ} \mathrm{C}$ até alcançarem massa constante, sendo então moídas. O procedimento para determinação de $\mathrm{N}$ na biomassa aérea baseou-se no método recomendado por Bremner \& Mulvaney (1982).

Em abril de 1999, foram coletadas amostras de parte aérea das leguminosas e das folhas de bananeira para quantificar a fixação biológica e a transferência de $\mathrm{N}$ das leguminosas para as bananeiras. Esses parâmetros foram estimados pela técnica de abundância natural de ${ }^{15} \mathrm{~N}$, descrita por Shearer \& Kohl (1986), sendo usado como controle o tratamento vegetação espontânea sem adubação nitrogenada nas bananeiras.

Durante o desenvolvimento das bananeiras, foram feitas medições mensais para o número de folhas emitidas, e trimestrais para a altura das plantas. Por ocasião da colheita dos cachos, as variáveis avaliadas foram: produtividade, peso do cacho, peso das pencas, número de frutos por cacho e número de pencas por cacho.

Por ocasião da formação dos cachos, foram coletadas amostras para análise foliar de acordo com a metodologia descrita por Alves et al. (1995). A análise de N seguiu o método de Bremner \& Mulvaney (1982), enquanto P e $\mathrm{K}$ foram determinados a partir de digestão nítricoperclórica (Bataglia et al., 1983). A determinação do $\mathrm{P}$ foi realizada por colorimetria, pela formação da cor azul do complexo fosfato-molibdato em presença de ácido ascórbico, e a do K, por espectrofotometria de absorção atômica (Embrapa, 1997). Por sua vez, as determinações de $\mathrm{Ca}$ e de $\mathrm{Mg}$ foram feitas por espectrofotometria de absorção atômica, depois da digestão nítrico-perclórica (Bataglia et al., 1983).

Os procedimentos estatísticos constaram da análise de variância e teste F. Nas fontes de variação, onde houve diferença significativa, aplicou-se o teste de ScottKnott a 5\% de probabilidade, para a comparação de médias.

\section{Resultados e Discussão}

Cudzu tropical e vegetação espontânea (formada por capim-colonião) destacam-se quanto à produção de matéria seca da parte aérea, apresentando valores superiores às demais leguminosas em até 55 e 67\%, respectivamente (Tabela 1). Apesar da elevada produção de biomassa apresentada pela vegetação espontânea, seus resíduos vegetais revelaram menor quantidade de $\mathrm{N}$ acumulado, em relação às leguminosas.
A avaliação da fixação biológica de $\mathrm{N}$ pelo método da abundância natural demonstrou maiores teores de $\mathrm{N}$ fixado para amendoim forrageiro e cudzu tropical (Tabela 1). Os valores médios obtidos para essas leguminosas superaram os do siratro em 28 e 48\%, respectivamente. O cudzu tropical também apresentou quantidade de $\mathrm{N}$ fixado estatisticamente superior às demais leguminosas. Embora não tenham sido encontradas diferenças estatísticas para teores de $\mathrm{N}$ transferido das leguminosas para as bananeiras, foram constatadas contribuições expressivas nos tratamentos, variando de 24 a $40 \%$, para siratro e amendoim forrageiro, respectivamente (Tabela 1).

Os resultados obtidos relacionados à fixação biológica foram menores que os observados em ensaio feito com as mesmas espécies, em condições edafoclimáticas semelhantes (Espindola et al., 2005). Tal redução foi particularmente verificada no siratro e, em menor extensão, no amendoim forrageiro, o que pode estar relacionado ao sombreamento proporcionado pelas bananeiras. Fujita et al. (1993) demonstraram que a fixação biológica diminui no siratro, quando submetido a condições de sombreamento, enquanto o cudzu tropical foi menos afetado nessas mesmas condições.

O desenvolvimento vegetativo da bananeira pode ser influenciado por diferentes fatores relacionados ao manejo agrícola, como a irrigação (Gonzaga Neto et al., 1993) e a densidade de plantio (Lichtemberg et al., 1997). Verificou-se, neste trabalho, que a altura das bananeiras foi afetada de forma marcante pela espécie usada como cobertura viva (Tabela 2). A partir do sétimo mês depois do plantio, as bananeiras consorciadas com as leguminosas amendoim forrageiro, cudzu tropical e

Tabela 1. Produção de matéria seca da parte aérea e quantidade de $\mathrm{N}$ acumulado em leguminosas herbáceas perenes e vegetação espontânea, proporção e quantidade de $\mathrm{N}$ fixado biologicamente pelas leguminosas (Nfbl) e proporção de $\mathrm{N}$ na bananeira, derivado da fixação biológica nas leguminosas (Ndfbl), obtidos a partir do somatório de valores acumulados dos três primeiros cortes ${ }^{(1)}$.

\begin{tabular}{lccccc}
\hline $\begin{array}{l}\text { Planta de } \\
\text { cobertura }\end{array}$ & $\begin{array}{c}\text { Matéria seca } \\
\left(\mathrm{Mg} \mathrm{ha}^{-1}\right)\end{array}$ & $\begin{array}{c}\mathrm{N} \text { acumulado } \\
\left(\mathrm{kg} \mathrm{ha}^{-1}\right)\end{array}$ & $\begin{array}{c}\mathrm{Nfbl} \\
(\%)\end{array}$ & $\begin{array}{c}\mathrm{N} \text { fixado } \\
\left(\mathrm{kg} \mathrm{ha}^{-1}\right)\end{array}$ & $\begin{array}{c}\text { Ndfbl da } \\
\text { bananeira (\%) }\end{array}$ \\
\hline Amend. forrageiro & $12,0 \mathrm{~b}$ & $296,1 \mathrm{~b}$ & $66,9 \mathrm{a}$ & $201,6 \mathrm{~b}$ & $40,5 \mathrm{a}$ \\
Cudzu tropical & $15,0 \mathrm{a}$ & $375,0 \mathrm{a}$ & $86,2 \mathrm{a}$ & $305,5 \mathrm{a}$ & $33,7 \mathrm{a}$ \\
Siratro & $9,7 \mathrm{~b}$ & $236,5 \mathrm{c}$ & $38,2 \mathrm{~b}$ & $89,3 \mathrm{c}$ & $24,2 \mathrm{a}$ \\
Veg. espontânea & $16,2 \mathrm{a}$ & $132,4 \mathrm{~d}$ & - & - & - \\
\hline
\end{tabular}

(1)Médias seguidas de letras iguais, na mesma coluna, não diferem entre si pelo teste de Scott-Knott a 5\% de probabilidade. 
siratro tiveram desenvolvimento mais rápido do que o observado nos tratamentos com vegetação espontânea (com adubação nitrogenada e sem adubação nitrogenada).

O número de folhas emitidas das bananeiras foi maior nas fruteiras desenvolvidas no solo coberto com as leguminosas cudzu tropical e siratro, em relação ao dos tratamentos com vegetação espontânea (com adubação nitrogenada e sem adubação nitrogenada), entre o terceiro e o oitavo mês depois do plantio (Tabela 3). A partir do décimo segundo mês, observou-se tendência das bananeiras desenvolvidas em solo com vegetação espontânea e com o amendoim forrageiro em superar outros tratamentos, quanto ao número de folhas emitidas. Isso pode ser entendido pelo fato de que, depois do décimo segundo mês de crescimento, as bananeiras que cresceram com cobertura de cudzu tropical e siratro iniciaram o processo de formação de cachos, reduzindo o número de folhas, enquanto as plantas com vegetação espontânea e amendoim forrageiro encontravam-se ainda em fase de crescimento vegetativo. Os resultados relacionados ao crescimento mais rápido das bananeiras consorciadas com as leguminosas cudzu tropical e siratro, assim como seu maior número de folhas até o oitavo mês de cultivo, evidenciam o efeito benéfico da cobertura com essas espécies no desenvolvimento vegetativo da bananeira.

Tabela 2. Altura (cm) das bananeiras em diversos períodos do desenvolvimento de bananeiras consorciadas com plantas de cobertura formadas por leguminosas herbáceas perenes e vegetação espontânea ${ }^{(1)}$.

\begin{tabular}{lrrrrrr}
\hline Planta de cobertura & \multicolumn{6}{c}{ Meses depois do plantio } \\
\cline { 2 - 7 } & 1 & 4 & \multicolumn{1}{c}{7} & \multicolumn{1}{c}{10} & \multicolumn{1}{c}{13} & 16 \\
\hline Amendoim forrageiro & $23,6 \mathrm{a}$ & $58,3 \mathrm{a}$ & $111,1 \mathrm{a}$ & $167,3 \mathrm{a}$ & $199,2 \mathrm{a}$ & $217,6 \mathrm{a}$ \\
Cudzu tropical & $22,5 \mathrm{a}$ & $62,1 \mathrm{a}$ & $137,7 \mathrm{a}$ & $195,0 \mathrm{a}$ & $211,3 \mathrm{a}$ & $215,8 \mathrm{a}$ \\
Siratro & $22,9 \mathrm{a}$ & $51,4 \mathrm{~b}$ & $142,6 \mathrm{a}$ & $192,0 \mathrm{a}$ & $204,8 \mathrm{a}$ & $211,6 \mathrm{a}$ \\
Vegetação espontânea & $21,9 \mathrm{a}$ & $36,9 \mathrm{c}$ & $49,1 \mathrm{~b}$ & $52,9 \mathrm{~b}$ & $63,4 \mathrm{~b}$ & $76,7 \mathrm{~b}$ \\
Vegetação espontânea + N & $22,9 \mathrm{a}$ & $49,0 \mathrm{~b}$ & $73,8 \mathrm{~b}$ & $86,3 \mathrm{~b}$ & $103,5 \mathrm{~b}$ & $122,8 \mathrm{~b}$ \\
\hline (1) Médias seguidas de letras iguais, na mesma coluna, não diferem entre \\
si pelo teste de Scott-Knott a 5\% de probabilidade.
\end{tabular}

Tabela 3. Número de folhas emitidas em diversos períodos do desenvolvimento de bananeiras consorciadas com plantas de cobertura formadas por leguminosas herbáceas perenes e vegetação espontânea ${ }^{(1)}$.

\begin{tabular}{lrrrrrr}
\hline Planta de cobertura & \multicolumn{7}{c}{ Meses depois do plantio } \\
\cline { 2 - 7 } & $1-2$ & \multicolumn{1}{c}{$3-5$} & $6-8$ & $9-11$ & $12-14$ & $15-16$ \\
\hline Amendoim forrageiro & $3,1 \mathrm{~b}$ & $9,6 \mathrm{~b}$ & $9,8 \mathrm{~b}$ & $6,9 \mathrm{a}$ & $7,2 \mathrm{a}$ & $2,3 \mathrm{a}$ \\
Cudzu tropical & $3,9 \mathrm{a}$ & $10,8 \mathrm{a}$ & $10,6 \mathrm{a}$ & $7,7 \mathrm{a}$ & $3,8 \mathrm{~b}$ & $0,4 \mathrm{~b}$ \\
Siratro & $2,9 \mathrm{~b}$ & $10,9 \mathrm{a}$ & $11,9 \mathrm{a}$ & $6,2 \mathrm{a}$ & $2,4 \mathrm{~b}$ & $1,1 \mathrm{~b}$ \\
Vegetação espontânea & $2,9 \mathrm{~b}$ & $8,1 \mathrm{c}$ & $6,8 \mathrm{c}$ & $5,2 \mathrm{~b}$ & $7,1 \mathrm{a}$ & $2,8 \mathrm{a}$ \\
Vegetação espontânea $+\mathrm{N}$ & $2,8 \mathrm{~b}$ & $9,7 \mathrm{~b}$ & $8,1 \mathrm{c}$ & $5,6 \mathrm{~b}$ & $7,3 \mathrm{a}$ & $2,8 \mathrm{a}$ \\
\hline
\end{tabular}

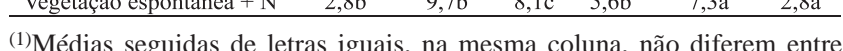
si pelo teste de Scott-Knott a 5\% de probabilidade.
Observaram-se maiores teores de $\mathrm{N}$ em folhas de bananeiras consorciadas com leguminosas em relação às da vegetação espontânea (Tabela 4). Processo semelhante foi constatado quanto aos teores de Ca das folhas de bananeiras consorciadas com cudzu tropical e siratro. Considerando que as leguminosas apresentam taxa de liberação mais rápida de $\mathrm{N}$ e Ca durante a decomposição dos seus resíduos vegetais, quando comparado ao capim-colonião (Espindola, 2001), é possível que esse processo explique os teores descritos.

A proporção de cachos colhidos e época de colheita também foram afetados pelo uso de plantas de cobertura (Tabela 5). Em todas as bananeiras que cresceram no solo com cobertura de leguminosas, a colheita dos cachos foi realizada até aproximadamente 20 meses depois do plantio das mudas. Por outro lado, em $87 \%$ das bananeiras não foi efetuada a colheita dos cachos aos 26 meses, quando o solo encontrava-se coberto com vegetação espontânea. Quando as bananeiras foram adubadas com N, a proporção de cachos colhidos aumentou, mas mostrou-se ainda inferior à observada na presença das leguminosas. A precocidade da colheita é uma característica desejável, por determinar maior rapidez no retorno dos investimentos realizados.

A cobertura do solo com leguminosas proporcionou aumentos na produtividade, no número de frutos por

Tabela 4. Teores de nutrientes das folhas de bananeiras consorciadas com plantas de cobertura formadas por leguminosas herbáceas perenes e vegetação espontânea ${ }^{(1)}$.

\begin{tabular}{lrrrrr}
\hline Planta de cobertura & $\mathrm{N}$ & $\mathrm{P}$ & $\mathrm{K}$ & $\mathrm{Ca}$ & $\mathrm{Mg}$ \\
\hline Amendoim forrageiro & $26,8 \mathrm{a}$ & $1,48 \mathrm{c}$ & $15,9 \mathrm{c}$ & $9,1 \mathrm{c}$ & $3,74 \mathrm{~b}$ \\
Cudzu tropical & $27,6 \mathrm{a}$ & $1,54 \mathrm{c}$ & $13,2 \mathrm{~d}$ & $12,2 \mathrm{a}$ & $4,34 \mathrm{a}$ \\
Siratro & $27,3 \mathrm{a}$ & $1,51 \mathrm{c}$ & $16,0 \mathrm{c}$ & $10,7 \mathrm{~b}$ & $4,32 \mathrm{a}$ \\
Vegetação espontânea & $5,2 \mathrm{c}$ & $1,97 \mathrm{~b}$ & $21,9 \mathrm{a}$ & $8,2 \mathrm{c}$ & $4,13 \mathrm{a}$ \\
Vegetação espontânea $+\mathrm{N}$ & $20,2 \mathrm{~b}$ & $2,25 \mathrm{a}$ & $19,8 \mathrm{~b}$ & $9,7 \mathrm{c}$ & $4,14 \mathrm{a}$ \\
\hline
\end{tabular}

(1)Médias seguidas de letras iguais, na mesma coluna, não diferem entre si pelo teste de Scott-Knott a 5\% de probabilidade.

Tabela 5. Proporção de cachos colhidos e época de colheita observados em bananeiras consorciadas com plantas de cobertura formadas por leguminosas herbáceas perenes e vegetação espontânea ${ }^{(1)}$.

\begin{tabular}{lcc}
\hline Planta de cobertura & $\begin{array}{c}\text { Época de colheita } \\
\text { (meses depois do plantio) }\end{array}$ & $\begin{array}{c}\text { Cachos colhidos } \\
(\%)\end{array}$ \\
\hline Amendoim forrageiro & $19,5 \mathrm{c}$ & $100,0 \mathrm{a}$ \\
Cudzu tropical & $17,5 \mathrm{~d}$ & $100,0 \mathrm{a}$ \\
Siratro & $15,8 \mathrm{e}$ & $100,0 \mathrm{a}$ \\
Vegetação espontânea & $26,0 \mathrm{a}$ & $12,5 \mathrm{~b}$ \\
Vegetação espontânea $+\mathrm{N}$ & $21,6 \mathrm{~b}$ & $43,8 \mathrm{~b}$ \\
\hline
\end{tabular}

(1)Médias seguidas de letras iguais, na mesma coluna, não diferem entre si pelo teste de Scott-Knott a 5\% de probabilidade. 
cacho e de pencas por cacho das bananeiras, em relação ao uso de vegetação espontânea (Tabela 6). As leguminosas cudzu tropical e siratro também proporcionaram aumentos na massa de cachos e de pencas, quando comparadas à vegetação espontânea.

O uso das leguminosas avaliadas neste trabalho resultou em aumento do crescimento vegetativo e da produção dos frutos das bananeiras, em relação à vegetação espontânea. Condições edafoclimáticas desfavoráveis podem, no entanto, ocasionar reduções na massa de cachos e no número de frutos por cacho em bananeiras consorciadas com leguminosas herbáceas perenes, como é relatado para essa fruteira cultivada em solo coberto com amendoim forrageiro. Uma das possíveis causas desses resultados é a competição por água entre a leguminosa e a bananeira (Johns, 1994).

Perin et al. (2002) demonstraram, sob condições edafoclimáticas semelhantes às deste trabalho, que menores teores de umidade são encontrados em solo coberto com amendoim forrageiro, quando comparado ao cultivo de cudzu tropical e siratro.

Entretanto, é necessário o acompanhamento do impacto da cobertura viva com leguminosas herbáceas perenes nos ciclos subseqüentes. Fisher \& Cruz (1993) ressaltaram o fato de que o sombreamento acarreta diferentes respostas fisiológicas nas leguminosas, afetando o processo da fotossíntese. Os resultados encontrados indicam que cudzu tropical e, em menor grau, amendoim forrageiro, são espécies tolerantes ao sombreamento, enquanto siratro apresenta maior sensibilidade quando submetido a condições de reduzida luminosidade (Fujita et al., 1993; Andrade \& Valentim, 1999). Esse aspecto pode acarretar problemas como a redução da cobertura do solo em bananais já formados, permitindo o avanço de espécies invasoras.

Tabela 6. Produtividade $\left(\mathrm{Mg} \mathrm{ha}^{-1}\right)$, massa de cachos e de pencas (kg), número de frutos por cacho e número de pencas por cacho em bananeiras consorciadas com plantas de cobertura formadas por leguminosas herbáceas perenes e vegetação espontânea ${ }^{(1)}$.

\begin{tabular}{lrrrrc}
\hline $\begin{array}{l}\text { Planta de } \\
\text { cobertura }\end{array}$ & $\begin{array}{c}\text { Produ- } \\
\text { tividade }\end{array}$ & $\begin{array}{c}\text { Massa de } \\
\text { cachos }\end{array}$ & $\begin{array}{c}\text { Massa de } \\
\text { pencas }\end{array}$ & $\begin{array}{c}\text { Número de } \\
\text { frutos por } \\
\text { cacho }\end{array}$ & $\begin{array}{c}\text { Número } \\
\text { de pencas } \\
\text { por cacho }\end{array}$ \\
\hline Amend. forrageiro & $7,7 \mathrm{a}$ & $8,9 \mathrm{~b}$ & $8,1 \mathrm{~b}$ & $89,6 \mathrm{a}$ & $6,6 \mathrm{a}$ \\
Cudzu tropical & $10,8 \mathrm{a}$ & $11,7 \mathrm{a}$ & $10,6 \mathrm{a}$ & $102,0 \mathrm{a}$ & $7,2 \mathrm{a}$ \\
Siratro & $12,6 \mathrm{a}$ & $14,4 \mathrm{a}$ & $13,1 \mathrm{a}$ & $117,6 \mathrm{a}$ & $8,0 \mathrm{a}$ \\
Veg. espontânea & $1,6 \mathrm{~b}$ & $2,9 \mathrm{~b}$ & $2,8 \mathrm{~b}$ & $21,5 \mathrm{~b}$ & $1,5 \mathrm{~b}$ \\
Veg. espontânea + N & $5,1 \mathrm{~b}$ & $7,3 \mathrm{~b}$ & $6,7 \mathrm{~b}$ & $60,5 \mathrm{~b}$ & $4,9 \mathrm{a}$ \\
\hline
\end{tabular}

(1)Médias seguidas de letras iguais, na mesma coluna, não diferem entre si pelo teste de Scott-Knott a 5\% de probabilidade.
O potencial benéfico das leguminosas cudzu tropical e siratro e, em menor extensão, do amendoim forrageiro, como coberturas vivas capazes de fornecer $\mathrm{N}$ derivado da fixação biológica, e ainda proporcionar aumentos na produtividade dos frutos, foi demonstrado no primeiro ciclo de produção de bananeiras cultivar Nanicão. Assim, essas espécies são alternativas promissoras para a sustentabilidade de bananais.

\section{Conclusões}

1. O cudzu tropical apresenta maior teor de $\mathrm{N}$ e quantidade de $\mathrm{N}$ acumulado provenientes da fixação biológica de nitrogênio.

2. A cobertura viva com as leguminosas amendoim forrageiro, cudzu tropical e siratro ocasiona aumento da altura das bananeiras consorciadas.

3. O uso da cobertura viva formada por amendoim forrageiro, cudzu tropical e siratro ocasiona aumento da produtividade e da proporção de cachos colhidos, e reduz o tempo até a colheita quando comparada à vegetação espontânea.

\section{Referências}

ALVES, E.J.; DANTAS, J.L.L.; SOARES FILHO, W. dos S.; SILVA, S. de O. e; OLIVEIRA, M. de A.; SOUZA, L. da S.; CINTRA, F.L.D.; BORGES, A.L.; OLIVEIRA, A.M.G.; OLIVEIRA, S.L. de; FANCELLI, M.; CODEIRO, Z.J.M.; SOUZA, J. da S. Banana para exportação: aspectos técnicos da produção. Brasília: EmbrapaSPI, 1995. 106p. (Série Publicações Técnicas Frupex, 18).

ANDRADE, C.M.S. de; VALENTIM, J.F. Adaptação, produtividade e persistência de Arachis pintoi submetido a diferentes níveis de sombreamento. Revista Brasileira de Zootecnia, v.28, p.439-445, 1999.

BATAGLIA, O.C.; FURLANI, A.M.C.; TEIXEIRA, J.P.F.; FURLANI, P.R.; GALLO, J.R. Métodos de análise química de plantas. Campinas: Instituto Agronômico, 1983. 48p. (Boletim técnico, 78).

BORGES, A.L.; OLIVEIRA, A.M.G.; SOUZA, L. da S. Solos, nutrição e adubação. In: ALVES, E.J. (Org.). A cultura da banana: aspectos técnicos, socioeconômicos e agroindustriais. Brasília: Embrapa-SPI; Cruz das Almas: Embrapa-CNPMF, 1997. p.197260.

BREMNER, J.M.; MULVANEY, C.S. Nitrogen total. In: PAGE, A.L. (Ed.). Methods of soil analysis: part 2. $2^{\text {nd }}$ ed. Madison: Soil Science Society of America, 1982. p.595-624.

CANELLAS, L.P.; ESPINDOLA, J.A.A.; GUERRA, J.G.M.; TEIXEIRA, M.G.; VELLOSO, A.C.X.; RUMJANEK, V.M. Phosphorus analysis in soil under herbaceous perennial leguminous 
cover by nuclear magnetic spectroscopy. Pesquisa Agropecuária Brasileira, v.39, p.589-596, 2004.

COSTA, M.B.B. da (Coord.). Adubação verde no Sul do Brasil. Rio de Janeiro: AS-PTA, 1993. 346p.

DERPSCH, R.; ROTH, C.H.; SIDIRAS, N.; KOPKE, U. Controle da erosão no Paraná, Brasil: sistemas de cobertura do solo, plantio direto e preparo conservacionista do solo. Londrina: GTZ-IAPAR, 1991. 272p.

EMBRAPA. Centro Nacional de Pesquisa de Solos (Rio de Janeiro, RJ). Manual de métodos de análise de solo. 2.ed. Rio de Janeiro, 1997. 212p.

ESPINDOLA, J.A.A. Avaliação de leguminosas herbáceas perenes usadas como cobertura viva do solo e sua influência sobre a produção da bananeira (Musa spp.). 2001. 144p. Tese (Doutorado) - Universidade Federal Rural do Rio de Janeiro, Seropédica.

ESPINDOLA, J.A.A.; GUERRA, J.G.M.; ALMEIDA, D.L. de; TEIXEIRA, M.G.; URQUIAGA, S. Evaluation of perennial herbaceous legumes with different phosphorus sources and levels in a Brazilian Ultisol. Renewable Agriculture and Food Systems, v.20, p.56-62, 2005.

ESPINDOLA, J.A.A.; OLIVEIRA, S.J.C.R. de; CARVALHO, G.J.A. de; SOUZA, C.L.M. de; PERIN, A.; GUERRA, J.G.M.; TEIXEIRA, M.G. Potencial alelopático e controle de plantas invasoras por leguminosas herbáceas perenes consorciadas com bananeira. Seropédica: Embrapa Agrobiologia, 2000. 8p. (Comunicado técnico, 47).

FISHER, M.J.; CRUZ, P. Some ecophysiological aspects of Arachis pintoi. In: KERRIDGE, P.C.; HARDY, B. (Ed.). Biology and agronomy of forage Arachis. Cali: Centro Internacional de Agricultura Tropical, 1993. p.53-70.
FUJITA, K.; MATSUMOTO, K.; OFOSU-BUDU, G.K.; OGATA, S. Effect of shading on growth and dinitrogen fixation of kudzu and tropical pasture legumes. Soil Science and Plant Nutrition, v.39, p.43-54, 1993.

GONZAGA NETO, L.; SOARES, J.M.; CRISTO, A.S.; NASCIMENTO, T. Avaliação de cultivares de bananeira na região do Submédio São Francisco. I. Primeiro ciclo de produção. Revista Brasileira de Fruticultura, v.15, p.21-25, 1993.

IBGE. Anuário estatístico do Brasil. Rio de Janeiro, 2002. v.60, p.3-25.

JOHNS, G.G. Effect of Arachis pintoi groundcover on performance of bananas in northern New South Wales. Australian Journal of Experimental Agriculture, v.34, p.1197-1204, 1994.

LICHTEMBERG, L.A.; HINZ, R.H.; MALBURG, J.L.; STUKER, H. Crescimento e duração dos cinco primeiros ciclos da bananeira Nanicão sob três densidades de plantio. Revista Brasileira de Fruticultura, v.19, p.15-23, 1997.

MEDINA, J.C.; BLEINROTH, E.W.; DE MARTIN, Z.J.; TRAVAGLINI, D.A.; OKADA, M.; QUAST, D.G.; HASHIZUME, T.; MORETTI, V.A.; BICUDO NETO, L.C.; ALMEIDA, L.A.S.B.; RENESTO, O.V. Banana: cultura, matéria-prima, processamento e aspectos econômicos. 2.ed. Campinas: Instituto de Tecnologia de Alimentos, 1995. 302p. (Frutas tropicais, 3).

PERIN, A.; GUERRA, J.G.M.; TEIXEIRA, M.G.; PEREIRA, M.G.; FONTANA, A. Efeito da cobertura viva com leguminosas herbáceas perenes na agregação de um argissolo. Revista Brasileira de Ciência do Solo, v.26, p.713-720, 2002.

SHEARER, G; KOHL, D.H. $\mathrm{N}_{2}$-fixation in field settings: estimations based on natural ${ }^{15} \mathrm{~N}$ abundance. Australian Journal of Plant Physiology, v.13, p.699-756, 1986. 